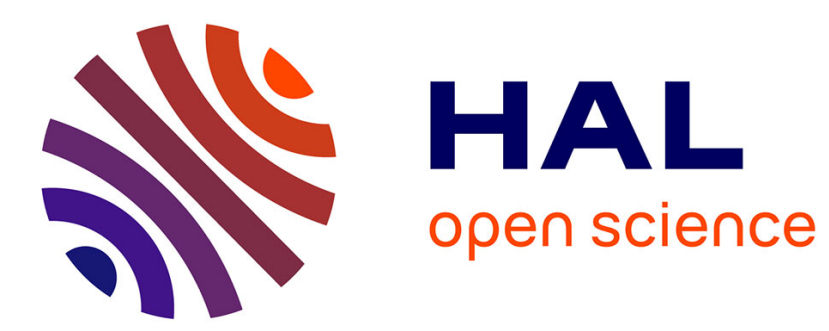

\title{
On controversy of behaviour of UF 6 cylinders exposed to fire: deeper examination of experimental results
}

\author{
F. Werkoff, André Bontemps, Alain Maréchal
}

\section{To cite this version:}

F. Werkoff, André Bontemps, Alain Maréchal. On controversy of behaviour of UF 6 cylinders exposed to fire: deeper examination of experimental results. Packaging, Transport, Storage \& Security of Radioactive Materials, 2006, 17, pp.165-171. 10.1179/174651006X130196 . hal-00189129

\section{HAL Id: hal-00189129 \\ https://hal.science/hal-00189129}

Submitted on 27 Mar 2020

HAL is a multi-disciplinary open access archive for the deposit and dissemination of scientific research documents, whether they are published or not. The documents may come from teaching and research institutions in France or abroad, or from public or private research centers.
L'archive ouverte pluridisciplinaire HAL, est destinée au dépôt et à la diffusion de documents scientifiques de niveau recherche, publiés ou non, émanant des établissements d'enseignement et de recherche français ou étrangers, des laboratoires publics ou privés. 


\title{
On controversy of behaviour of $\mathrm{UF}_{6}$ cylinders exposed to fire: deeper examination of experimental results
}

\author{
F. Werkoff*1, A. Bontemps ${ }^{2}$ and A. Maréchal ${ }^{1}$
}

The behaviour of a $48 \mathrm{Y}$ cylinder subjected to a regulatory fire of $800 \mathrm{uC}$ for $30 \mathrm{~min}$, in accordance with the criteria from the International Atomic Energy Agency, has been the subject of controversy for several years. Some claimed that if the $48 \mathrm{Y}$ cylinder is filled to the nominal value of $12 \cdot 5$ tonnes of $\mathrm{UF}_{6}$ and subjected to a $30 \mathrm{~min}$ fire, it would fail, according to an interpretation of the results from the TENERIFE experimental programme and a preliminary model. Others who did not have access to the TENERIFE results, claimed that the 48Y would not fail. A more in depth study showed that the preliminary model is not able to ascertain either the resistance or the failure of the $48 \mathrm{Y}$ cylinders subjected to the $30 \mathrm{~min}$ fire. This led the authors to revisit all the available experimental data and more particularly the results from the TENERIFE experimental programme and to look with particular care at the temperature inside the cylinder and to the pressure evolution after cessation of heating. It was concluded first that the temperatures inside the TENERIFE cylinder at the end of the heating period allow the preliminary model to be adjusted, and second that the simulation of the experimental results after approximately $2000 \mathrm{~s}$ by the preliminary model, was only possible by using non-physical and arbitrary numerical operations. Finally, a more realistic mechanism for the increase in pressure before and after cessation of heating is suggested.

Keywords: Regulatory fire, Rupture, 48 Y cylinder, TENERIFE

\section{Introduction}

The $48 \mathrm{Y}$ is a cylindrical steel body used for storing and transporting up to $12 \cdot 5$ tonnes of uranium hexafluoride (UF6). It has shaped ends, protective skirts and stiffener rings. The length of a $48 \mathrm{Y}$ cylinder is $L=3.81 \mathrm{~m}$, external diameter $D=1.25 \mathrm{~m}$, lateral surface area $S=15 \mathrm{~m}^{2}$ and its volume $V=4.67 \mathrm{~m}^{3}$. It has a $16 \mathrm{~mm}$ thick carbon steel wall and has been hydrostatically tested at $2 \cdot 8 \mathrm{MPa}$ internal pressure.

In 1996, the International Atomic Energy Agency (IAEA) issued the revised 'Regulations for the safe transport of radioactive material', , which included changes to the requirements for packages filled with uranium hexafluoride $\left(\mathrm{UF}_{6}\right)$ to resist, among other tests, exposure to the regulatory $800^{\circ} \mathrm{C}, 30 \mathrm{~min}$ duration fire test, without rupture. The test requires that the thermal environment be fully engulfing, with a surface absorptivity of the steel wall of the cylinder equal to a value of $0 \cdot 8$ and an average flame emissivity coefficient equal to $0 \cdot 9$. The thermal environment corresponding to this

\footnotetext{
${ }^{1}$ Maison de la Légion d'honneur, Route Des Loges, Saint-Germain-EnLaye, 78100, France

'Universite Joseph Fourier, BP N 5338041 Grenoble Cedex 9, France

*Corresponding author, email fw0612@clubobs.com
}

definition will be called the IAEA regulatory fire hereafter in the present study. For this revision of the transport regulations, a Franco-Japanese experimental programme called TENERIFE (TENuE d'un Réservoir Industriel au FEu - Fire Resistance of an Industrial Tank), was carried out and was described by Niel et $a .^{2,3}$

To interpret the experimental results of TENERIFE, a preliminary model was developed that was the subject of a thesis by Pinton. ${ }^{4}$ Numerical versions of this model were created, and the resulting programme was called DIBONA. In 1997, Niel et al. ${ }^{2,3}$ and in 1999, Sert and colleagues ${ }^{5,6}$ produced a simulation of the behaviour of $\mathrm{UF}_{6}$ inside a $48 \mathrm{Y}$ cylinder placed inside a regulation IAEA fire and filled to the nominal value. The main result was that the critical pressure, estimated at 4.61 MPa according to Anderson et al., ${ }^{7}$ could be reached before the end of the $0.5 \mathrm{~h}$ period.

Bearing in mind that most of the results cited above were published after the decision was made to modify the transport regulations, other researchers who did not have access to the TENERIFE results claimed that the $48 \mathrm{Y}$ would not fail. Many of them were professionals experienced in handling $\mathrm{UF}_{6}$. However, their views were based on various 
experimental observations which were different from the conditions of the IAEA regulatory fire, rather than the results of the TENERIFE tests.

Re-examination of the thermal behaviour of the $48 \mathrm{Y}$ cylinders is the subject of this article. As in any subject of controversy, it is not possible to have perfect objectivity, but the opinion of the authors is that this re-examination reinforces the view of those who believe that the $48 \mathrm{Y}$ would not fail.

The qualitative work of Pinton ${ }^{4}$ will be briefly reviewed. The difficulty of its extrapolation (as done by Niel et al. ${ }^{2,3}$ in 1997 and Sert and colleagues ${ }^{5,6}$ in 1999 in their preliminary model) to the $48 \mathrm{Y}$ cylinder subjected to a regulatory fire will be recalled.

Baze et $a l .{ }^{8}$ demonstrated that the Niel and Sert preliminary modelling could not accurately predict the behaviour of a $48 \mathrm{Y}$ cylinder subjected to a fire. However, Baze et al. ${ }^{8}$ only took into account the limited experimental data considered by Niel and Sert. The present paper will examine the temperatures inside the TENERIFE cylinders with the goal of removing the ambiguities of the preliminary model that Baze et al. pointed out.

With the aim of bringing additional elements into the estimation of the fire resistance of the $48 \mathrm{Y}$ cylinders, an analysis will be presented based on several available experimental results. This will show another limitation of the preliminary model applied to the TENERIFE results after cessation of the heating.

Considering all the limitations of the preliminary model after the beginning of the nucleate boiling regime, an alternative mechanism for the increase in pressure will be discussed.

\section{Qualitative analysis of behaviour of $48 \mathrm{Y}$ cylinder filled to nominal value}

\section{Simulations of TENERIFE tests}

The Franco-Japanese experimental programme was carried out with the objective of obtaining information on the fire resistance of the $48 \mathrm{Y}$ cylinders filled to the nominal value of $12 \cdot 5$ tonnes. To interpret the experimental results of TENERIFE, a model was developed. ${ }^{4}$ This model describes many of the thermohydraulic phenomena that may be produced inside a cylinder filled with $\mathrm{UF}_{6}$ and subjected to a fire. Those phenomena taken into account are: the initial presence of a solid crust over the whole of the wall, the collapse of this crust when the pressure inside the cylinder equals the pressure at the triple point, the appearance of very high temperature gradients with extensive heating of the wall, the simultaneous presence of the solid, liquid and gaseous phases of $\mathrm{UF}_{6}$ inside the cylinder, and the change in the temperature of the wall at the bottom of the cylinder corresponding to various bubbling phenomena on the wall. Pinton ${ }^{4}$ pointed out the existence of five regimes in the TENERIFE tests:

(i) before the collapse of the crust

(ii) film boiling

(iii) transition boiling

(iv) nucleate boiling

(v) natural convection, after cessation of heating.

As a result of the difficulty in quantitatively describing several phenomena, some arbitrary choices were made and clearly indicated by Pinton. ${ }^{4}$

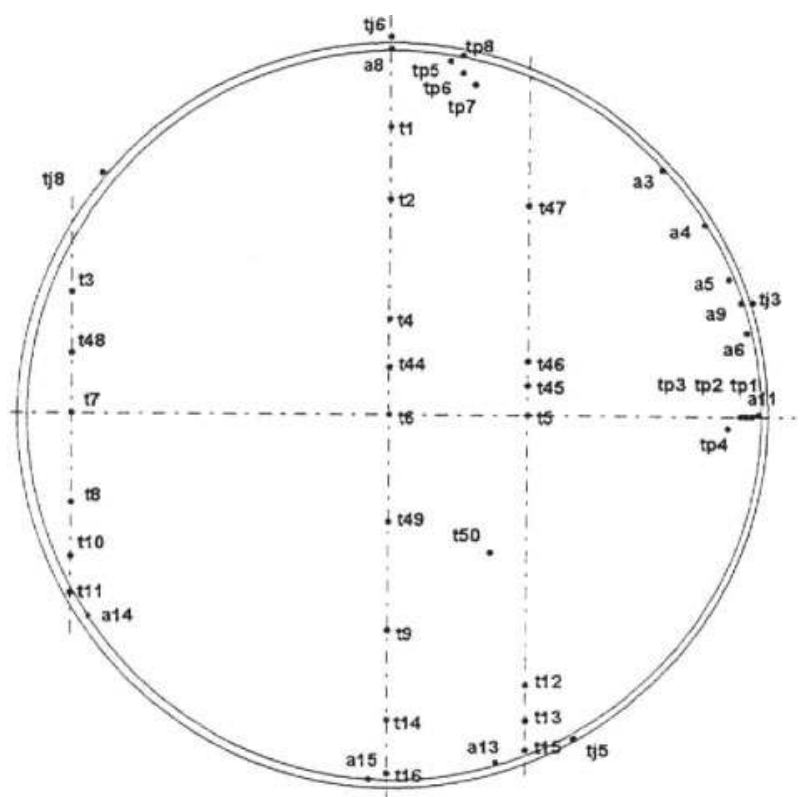

1 Instrumentation of the TEN4 container in the median plan: positions of thermocouples (reprinted from Ref. 13)

Although Niel et al. $^{2,3}$ and Sert and colleagues 5,6 consider that only the first four regimes reach values higher than $4 \mathrm{MPa}$ before cessation of heating in their simulations of the $48 \mathrm{Y}$ cylinder, for natural convection, there are matters of interpretation because:

(i) there is some indication that, for the TEN4 test, natural convection may have started in the lower part of the cylinder, before the end of heating, i.e. the cylinder wall temperature at the bottom (location A15; Fig. 1) shows a small increase from $1000 \mathrm{~s}$, to the end of heating; and

(ii) as later shown in the present study, the TENERIFE test results for the long period of time after cessation of heating could be explained by a mechanism other than natural convection.

Finally, recalibration of the software originally developed by Pinton, ${ }^{4}$ on the experimental results of the TEN4 TENERIFE test was carried out by adjustment of an equivalent increased conductivity in the $\mathrm{UF}_{6}$ liquid. The value of this conductivity is adjusted depending on the regime. Pinton used a conductivity equal to $1000 \mathrm{~W} \mathrm{~m}^{-1} \mathrm{~K}^{-1}$, during the regimes of film boiling and transition boiling. During nucleate boiling in Pinton's simulation, the conductivity gradually decreased from $1000 \mathrm{~W} \mathrm{~m}^{-1} \mathrm{~K}^{-1}$ to a certain value

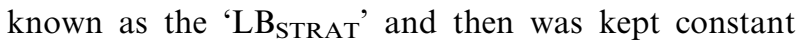
during the remainder of the nucleate boiling period. Pinton set the $\mathrm{LB}_{\mathrm{STR}}$ at value equal to $30 \mathrm{~W} \mathrm{~m}^{-1} \mathrm{~K}^{-1}$. It appeared however that in the TEN4 test, the periods for the film boiling and the transition boiling regimes start in the time period of approximately $800 \mathrm{~s}$ and end in the time period of approximately $1040 \mathrm{~s}$, whereas the period between the start of the nucleate boiling regime and stoppage of heating was placed between the times $t=1140$ and $1170 \mathrm{~s}$. Given the gradual decrease in conductivity, the LB STRAT $_{\text {'bearing' value is only used }}$ for approximately $30 \mathrm{~s}$, from 1140 to $1170 \mathrm{~s}$ (see Figure $6 \cdot 17$ of Pinton ${ }^{4}$ ). 


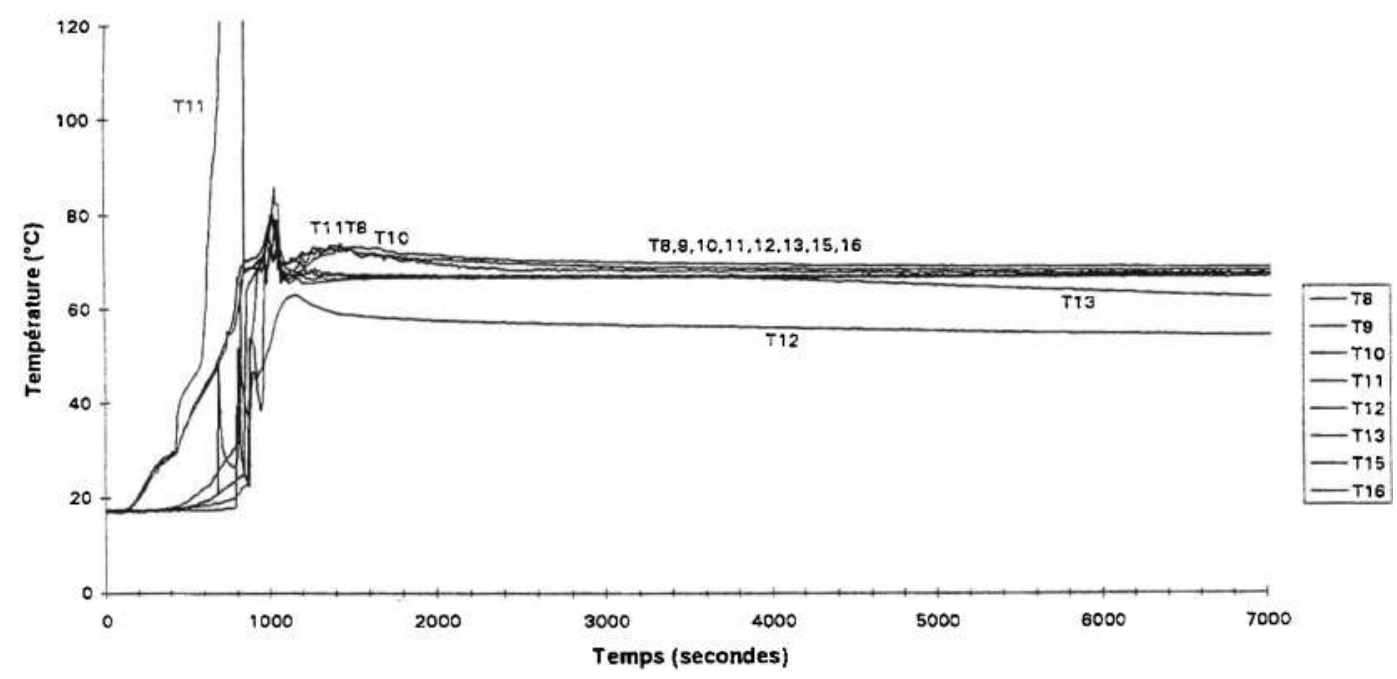

2 Experimental observation of temperatures below free surface and inside $\mathrm{UF}_{6}$, for TEN4 container (reprinted from Ref. 13)

\section{Removing ambiguity in use of preliminary model in $48 \mathrm{Y}$ cylinders}

Baze et $a l^{8}$ produced a new computer program of the preliminary model presented by Pinton. ${ }^{4}$ Noting the very short duration of the LB STRAT bearing value referred to in Fig. 1 of Baze et al. ${ }^{8}$ and Fig. 6.17 of Pinton, ${ }^{4}$ simulations of TEN4 were carried out by Baze et al., using two different values for LB STRAT: $_{\text {LB }}$ LBRAT $_{\text {STR }}=200 \mathrm{~W} \mathrm{~m}^{-1} \mathrm{~K}^{-1}$ and LB $_{\text {STRAT }}=$ $15 \mathrm{~W} \mathrm{~m}^{-1} \mathrm{~K}^{-1}$. These two values were chosen to provide upper and lower bounds to the original value of $30 \mathrm{~W} \mathrm{~m}^{-1} \mathrm{~K}^{-1}$. The changes in pressure over time, shown in Fig. 2 of Baze et al., ${ }^{8}$ agree well for the three

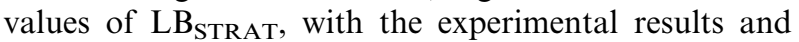
those results produced by the initial simulation. The LB $B_{\text {STRAT }}$ 'bearing' value was used for time periods greater than $1000 \mathrm{~s}$ for the simulation of the $48 \mathrm{Y}$ cylinder fire resistance. Simulations of a $48 \mathrm{Y}$ package subjected to a fire of $30 \mathrm{~min}$ duration led to very different changes in pressure: the pressure was only $2.4 \mathrm{MPa}$ at $1800 \mathrm{~s}$ for a value LB $_{\text {STRAT }}=$ $200 \mathrm{~W} \mathrm{~m}^{-1} \mathrm{~K}^{-1}$, but the critical pressure (4.61 MPa) was reached at around $1300 \mathrm{~s}$ for a value $\mathrm{LB}_{\text {StRAT }}=15 \mathrm{~W} \mathrm{~m}^{-1} \mathrm{~K}^{-1}$ (see Fig. 3 of Baze et al. ${ }^{8}$ ). All of these results obey the principles of energy conservation. According to Baze et al., ${ }^{8}$ with a value $\mathrm{LB}_{\text {STRAT }}=200 \mathrm{~W} \mathrm{~m}^{-1} \mathrm{~K}^{-1}$, almost all the solid section of $\mathrm{UF}_{6}$ has melted at $1500 \mathrm{~s}$.

As it was possible to correctly simulate the behaviour of the pressure in the TEN4 cylinder with very different values of $\mathrm{LB}_{\mathrm{STRAT}}$, before cessation of heating, other physical parameters were evaluated, while noting that there were measurements of the temperatures inside the TEN4 cylinder. Figure 1 shows the positions of the thermocouples and Fig. 2 the observed evolution of the temperature. For T8 to T16, eight of nine indicated temperature values a few degrees above the melting value $\left(64^{\circ} \mathrm{C}\right)$ after $1100 \mathrm{~s}$. The remaining thermocouple (T12) registered a temperature of the order of $55^{\circ} \mathrm{C}$. This clearly indicates the possibility of a solid portion in the lower part of the cylinder as the $\mathrm{UF}_{6}$ is reduced.

Moreover, although not considered either by Niel et al. ${ }^{2,3}$ or by Sert and colleagues, ${ }^{5,6}$ Pinton $^{4}$ had earlier provided simulated values of temperatures for positions corresponding to T8-T16 thermocouples. The modelled

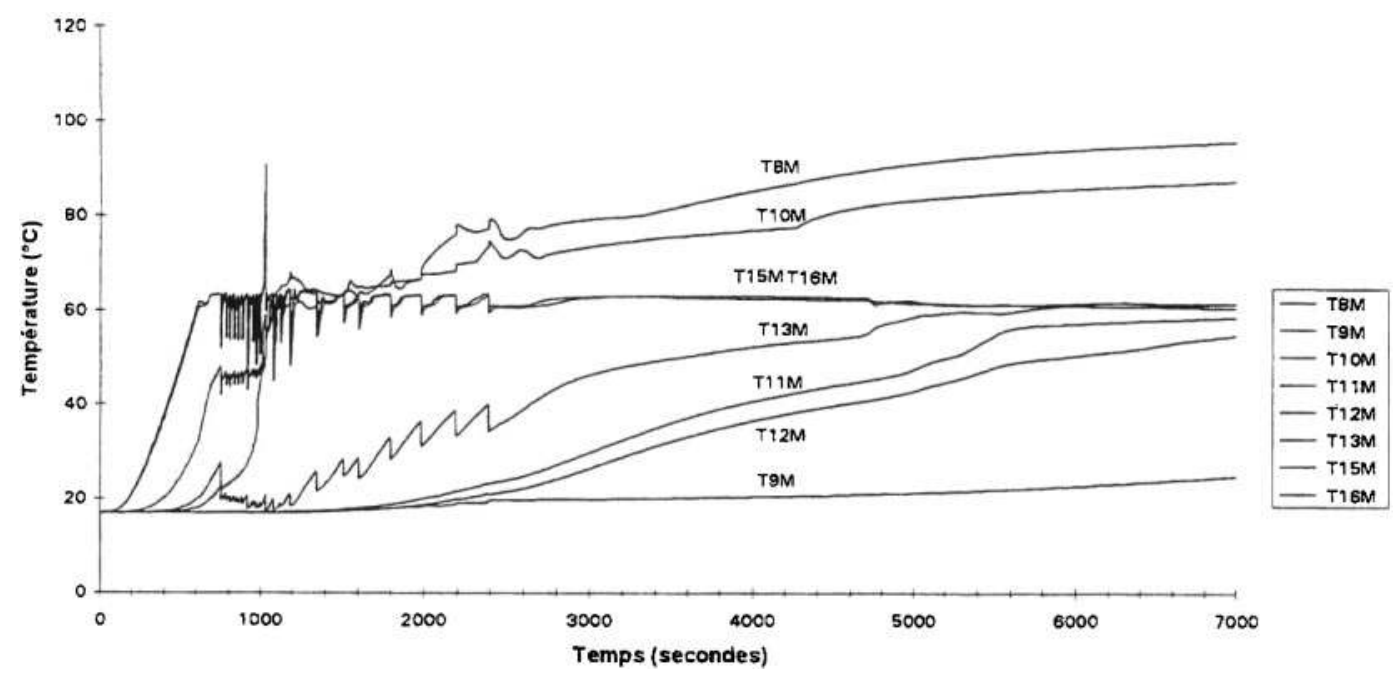

3 Numerical simulation, with preliminary model and $\mathrm{LB}_{\mathrm{STRAT}}=30 \mathrm{~W} \mathrm{~m} \mathrm{~m}^{-1} \mathrm{~K}^{-1}$, of temperatures below free surface and inside $\mathrm{UF}_{6}$, for TEN4 container (reprinted from Ref. 13) 
values, obtained by the preliminary model, with $\mathrm{LB}_{\text {STRAT }}=30 \mathrm{~W} \mathrm{~m}^{-1} \mathrm{~K}^{-1}$, are shown in Fig. 3. The corresponding $\mathrm{T} 8 \mathrm{M}$ to $\mathrm{T} 16 \mathrm{M}$ values thus modelled are quite different from the experimental results. T9M to $\mathrm{T} 16 \mathrm{M}$ values indicated that for a long time (up to more than $4000 \mathrm{~s}$ ), temperatures would be lower than $64^{\circ} \mathrm{C}$. That would correspond to the existence of a large $\mathrm{UF}_{6}$ solid core. Looking at the results reported by Baze et al., the existence of a solid core would be coherent with $\mathrm{LB}_{\text {STRAT }}=15 \mathrm{~W} \mathrm{~m}^{-1} \mathrm{~K}^{-1}$. Conversely, compared with the experimental observations reported in Fig. 2, the results for $\mathrm{LB}_{\mathrm{STRAT}}=200 \mathrm{~W} \mathrm{~m}^{-1} \mathrm{~K}^{-1}$ indicate the possibility of only a very small $\mathrm{UF}_{6}$ solid core. Among all the simulations of TEN4 using the preliminary model with various values of $\mathrm{LB}_{\mathrm{STRAT}}$, only the simulation performed with $\mathrm{LB}_{\mathrm{STRAT}}=200 \mathrm{~W} \mathrm{~m}^{-1} \mathrm{~K}^{-1}$ reproduces the experimental values for both the pressure as well as the temperature inside the lower part of the cylinder.

The simulation of the $48 \mathrm{Y}$ cylinder by Baze et al. ${ }^{8}$ (see their Fig. 3, with $\mathrm{LB}_{\mathrm{STRAT}}=200 \mathrm{~W} \mathrm{~m}^{-1} \mathrm{~K}^{-1}$ ) showed a pressure slightly less than $2.5 \mathrm{MPa}$ at $30 \mathrm{~min}$. As indicated by Sert and colleagues, ${ }^{5,6}$ experimental tests complementary to the TENERIFE program were performed on a pressurised vessel with no $\mathrm{UF}_{6}$. The related experimental results showed that the acceptable limit for the pressure inside the $48 \mathrm{Y}$ cylinder submitted to a regulatory IAEA fire should be somewhat higher than $4 \mathrm{MPa}$.

Thus, for the application of the preliminary model using a value of $\mathrm{LB}_{\mathrm{STRAT}}=200 \mathrm{~W} \mathrm{~m}^{-1} \mathrm{~K}^{-1}$ the resulting predicted temperatures contradict existing temperature data and the assertions of Niel et al..$^{2,3}$ and Sert and colleagues. ${ }^{5,6}$ Conversely, in an IAEA fire, the adjusted model predicts that the cylinder pressure will not reach the value expected to rupture the cylinder by the end of the regulatory fire test period of $30 \mathrm{~min}$.

As it is clear that all the available experimental data were not fully considered in the previous studies using the preliminary model, it was decided to revisit all the TENERIFE experimental results, and to explore in depth, complementary experimental results, in addition to the TENERIFE data.

\section{TENERIFE test limits}

The number of TENERIFE tests was limited to six. Only four significant tests: TEN2, TEN4, TEN5 and TEN6, were carried out using cylinders filled with $\mathrm{UF}_{6}$. For TEN2, the two pressure sensors provided very different indications; at comparable times, the average between the two values was chosen by Niel et al..$^{2,3}$ as the reference value, although it would have been preferable to consider only the maximum value, because the other transducer reads a maximum value beyond its range.

\section{Boiling of liquid $\mathrm{UF}_{6}$ in contact with overheated wall}

The application of the laws of boiling for a liquid in contact with a heated wall posed problems: first, due to the use of laws derived from experiments carried out using fluids other than $\mathrm{UF}_{6}$ (mainly water) and second due to a failure to recognise the phenomena of reabsorption of the created bubbles. In the DIBONA model, below an angle of $\theta_{\mathrm{c}}$ (defined as the angle between the lower part of the vertical axis and the point of interest on the wall), all of the bubbles created are reabsorbed, whereas above $\theta_{\mathrm{c}}$ all of the bubbles created are fed into a gaseous mass in the upper section of the cylinder. Pinton ${ }^{4}$ arbitrarily chose $\theta_{\mathrm{c}}=70^{\circ}$. The recalibration of the simulations on the experimental results of the TEN4 TENERIFE test was carried out by adjusting the increased equivalent conductivity in the liquid $\mathrm{UF}_{6}$ and always used $\theta_{\mathrm{c}}=70^{\circ}$. For the four tests, the filling levels were similar and no convincing argument exists regarding the use of a particular value of $\theta_{c}$; a different choice would allow the modelling to reproduce the results of TEN4, with the use of different values for the equivalent conductivity in the liquid $\mathrm{UF}_{6}$.

\section{Pressure evolution after cessation of heating}

For the four significant tests, the duration of the heating period was too short (especially the nucleated boiling sequence) to be truly applicable to the $48 \mathrm{Y}$ cylinders.

The premature halt in heating during the tests was due to the triggering of an automatic safety procedure imposed at the test facility, the objective of which was to prevent any risk of rupture. The maximum pressure at the point of cessation of heating for test TEN2 was $1.2 \mathrm{MPa}$ according to Niel et al., ${ }^{2,3}$ or more reasonably $2 \cdot 9 \mathrm{MPa}$ when considering the only working transducer.

The pressure continued to increase following the halt in heating. Para. 728(b) of the IAEA Regulations specifies that exposure to ambient conditions shall continue following the $30 \mathrm{~min}$ fire exposure '...for a sufficient period to ensure that temperatures in the specimen are everywhere decreasing...'. This implies decreasing temperatures within the test specimen, not just at the surface. Decreasing temperatures throughout imply decreasing pressures. In the numerical simulations of the TENERIFE results with the preliminary model, restoration of the change in pressure following the halt in heating led to the use of an LB $_{\text {STRAT }}$ decreasing with time for the equivalent increased conductivity in the liquid $\mathrm{UF}_{6}$, as shown in Fig. 1 in Baze et al. ${ }^{8}$

However, with the computerised tool of Baze et al., ${ }^{8}$ it was not possible to reproduce the experimental results of TEN4 after $2000 \mathrm{~s}$, whereas Niel et $a l^{2,3}$ and Sert and colleagues $^{5,6}$ asserted that they could. A detailed analysis of the numerical tool used for this restitution was performed by Blanchard ${ }^{9}$ and reported by Werkoff. $^{10,11}$ The conclusion of the observation of Blanchard (a specialist of the ANSYS language) was that - although it was neither explained nor justified by Niel et $a l^{2,3}$ and Sert and colleagues ${ }^{5,6}$ the reproduction was only possible by using an additional adjustment of the liquid conductivity inside a band, composed of very thin elements, located between the steel wall and the $\mathrm{UF}_{6}$ liquid. Inside each element, the value of the conductivity changes depending on the boiling regime. For the nucleate boiling regime, the value is bounded between 2500 and $30 \mathrm{~W} \mathrm{~m}^{-1} \mathrm{~K}^{-1}$. At each time step, if the difference between the saturation temperature and the temperature of the $\mathrm{UF}_{6}$ (in front of the element) is lower than $3 \mathrm{~K}$, the value of the conductivity is multiplied by a factor of two and if the difference is greater than $6 \mathrm{~K}$, it is multiplied by a factor $0 \cdot 8$. This artificial procedure generates the oscillations reported in Fig. 4, for various points along the band.

As a matter of fact, after cessation of heating, the wall temperatures decrease and after a certain delay (very short, when compared to the time of the pressure increase), all the parts of the wall between the angle $\theta_{\mathrm{c}}$ 


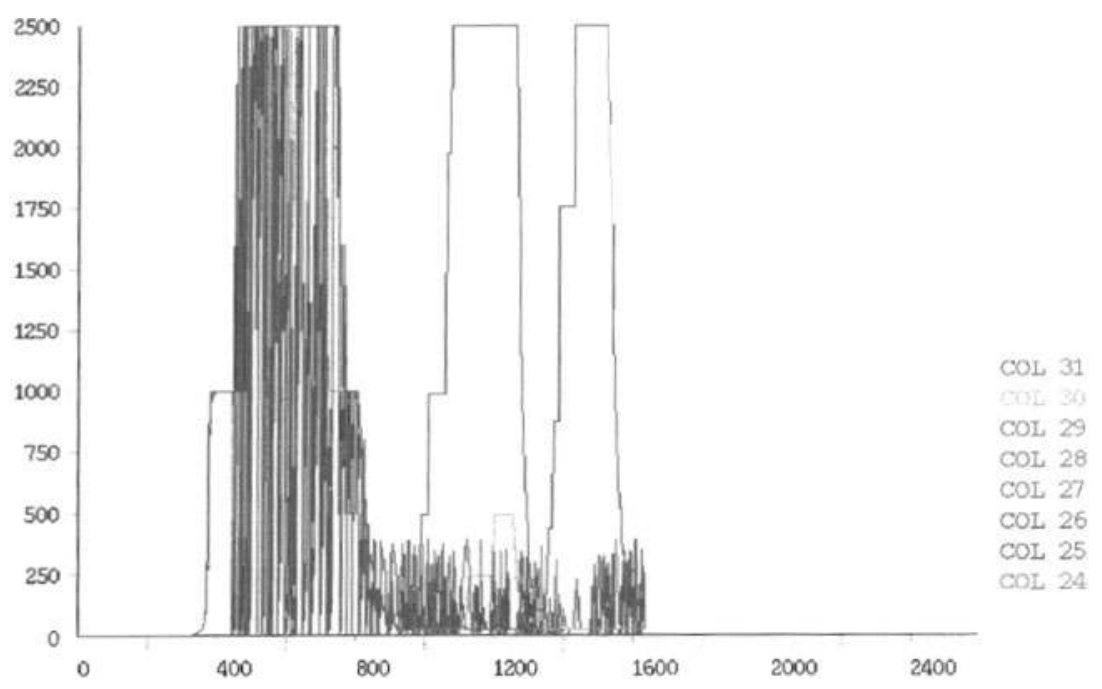

4 Evolution of conductivity (used by Niel et $a^{2,3}$ and Sert and colleagues ${ }^{5,6}$ ), in the elements of the strip band at the level of the free surface liquid/vapour, as a function of time [s] (reprinted from Ref. 9)

and the liquid/vapour surface are below the saturation temperature. For the results of the simulations to correlate with the experimental observations, the only place where it is possible to have boiling in contact with the wall is the point (or in the numerical model, the corresponding element of the band) at the level of the liquid/vapour surface. The aforementioned procedure drives the required quantity of heat from the upper part of the wall, to reproduce the TEN4 results. No attempts were made to apply the procedure to the other TENERIFE tests.

Sert and colleagues ${ }^{5,6}$ reported simulations of a $48 \mathrm{Y}$ cylinder, with cessation of heating at 20,25 and $30 \mathrm{~min}$. For these simulations, the automatic (and quite artificial) adjustment of the conductivity was not applied; for the 20 and 30 min simulations, immediate changes in the slope of the simulated curves of the time evolutions very quickly flattened. It was on the basis of this observation that thermal protection was recommended in order to fulfil the IAEA recommendations. The immediate change in the pressure evolution was never observed physically, either in the TEN4, TEN2, or in the TEN5 test performed with fire protection, or in an additional experiment with a simulant fluid performed in 1997 by Wataru et al. $;^{12}$ the immediate change in pressure was only observed with the DIBONA model when the automatic adjustment of the conductivity was not applied.

\section{Influence of fire protection}

In the TEN5 test, the rounded ends of the cylinder were protected by metal covers that led to almost no pressure increase when exposed to fire. Pinton ${ }^{13}$ questioned the influence of the covers on the $48 \mathrm{Y}$ cylinders based on the observation that the surface of a $48 \mathrm{Y}$ cylinder protected by metal covers could be $20 \%$, whereas it was $60 \%$ for TEN5 (since the test device was not the full length of the $48 \mathrm{Y}$ cylinder). Following an examination of the TEN5 results, Werkoff ${ }^{10,11}$ pointed out that, for this test and after cessation of heating, at first there was a slow pressure decrease followed by a long-lived strong pressure increase, for which no one has attempted to give an explanation (at least qualitative) using LB $_{\text {STRAT }}$ and $\theta_{\mathrm{c}}$.

\section{Experimental data obtained with simulant fluid}

The insufficient number and time exposure durations of tests in the TENERIFE programme are the result of difficulties in handling $U_{6}$, perceived safety concerns at the test facility, and the resulting costs. During all the TENERIFE tests, the heating was stopped too early. The reason was that the operators feared that the pressure would continue to grow for a long time after the cessation of heating and that they would have no means of stopping this increase. By using a simulant fluid, not subjected to these technological constraints, and at a reasonable cost, in small cylinders, it was decided that a number of important tests should be carried out that could provide answers to the questions mentioned in the preceding discussion. Experiments using perfluorohexane $\left(\mathrm{C}_{6} \mathrm{~F}_{12}\right)$ were carried out by Wataru et al. ${ }^{12}$ This fluid has a triple point that is very close to that of $\mathrm{UF}_{6}$. The results of the experiments showed characteristics that were qualitatively in agreement with those of the TENERIFE tests, in particular: the changes in the temperatures at the bottom point of the cylinder with time, which are indicative of various stages of boiling and the tracking of the increase in pressure following the cessation of heating. However, it is noted that the Stefan dimensionless number (defined as the ratio of sensible and latent heat) is appreciably much greater for $\mathrm{C}_{6} \mathrm{~F}_{12}$ than for $\mathrm{UF}_{6}$.

\section{More realistic mechanism for increase in pressure}

Werkoff ${ }^{10,11}$ has examined many complementary experimental results in addition to the TENERIFE results. Some of them were obtained using $\mathrm{UF}_{6}$, others with a simulant fluid. In all cases, the increase in pressure continued for a long time after the cessation of heating*, even in cases for which the temperature inside the cylinder was always lower than the temperature of the triple point, which means that only gas and solid coexisted. All these observations led to the conclusion that the main cause of the increase in the quantity of gas in the upper part of the cylinder was the evaporation on 


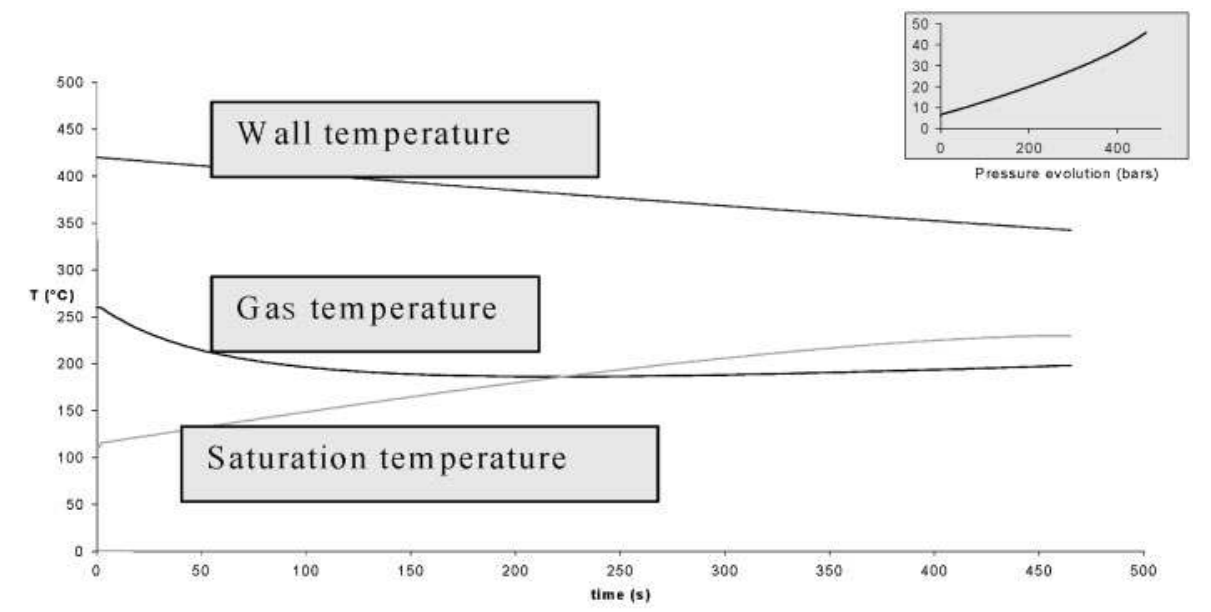

5 Temperature evolution from Fourmigué; ${ }^{14}$ after cessation of heating, container wall is still hot (more than $400^{\circ} \mathrm{C}$ ), and can transfer heat to the liquid surface by radiation; a simple numerical model taking into account this phenomenon and evaporation at liquid surface leads to an increase in pressure in the container (reprinted from Ref. 9)

the liquid/vapour surface (except for the transition and boiling regimes). The thermal exchanges between the wall and the liquid led mainly to an absorption of the created bubbles. This hypothesis is corroborated by the numerical simulations by Fourmigué ${ }^{14}$ (Fig. 5).

Figure 5 shows the evolution of temperatures and pressure with time for one simulation. It appears that the amount of heat in the cylinder wall is largely sufficient to explain the pressure increase and that other phenomena (re-condensation for example) must limit it.

To complement this simulation, Fluent software was used to simulate natural convection in liquid and gas phases. The results showed that convection is not a significant factor for heat transfer (low velocities), when compared to the heat radiated from the upper wall through the gas. In the liquid phase, reticulations can explain the temperature differences at the surface, and so give simultaneous evaporation and condensation.

\section{Perspectives and conclusion}

All the interpretations of the experimental results of TENERIFE, as well as the aforementioned numerical simulations used the analytical formulas for the physical properties of $\mathrm{UF}_{6}$ proposed by Anderson et al., ${ }^{7}$ which clearly indicated possible inaccuracies: 'Property data for $\mathrm{UF}_{6}$ around and beyond the critical point is practically nonexistent; therefore, correlations must be developed to predict the thermophysical properties of $\mathrm{UF}_{6}$ over these ranges'. Using thermodynamic measurements, optical measurements of transmission and phase plots carried out between 1940 and 1960, restricted to a narrow range of temperature and pressure, these analytical formulas were obtained by a technique of standardisation in relation to a point defined at a temperature close to boiling $\left(64^{\circ} \mathrm{C}\right)$. Today, it is freely admitted that such a method produces errors of the order of $10 \%$ over the critical pressure and temperature. It is reasonable to think that for $\mathrm{UF}_{6}$, this value might be easily exceeded given the $20 \%$ difference at $100^{\circ} \mathrm{C}$ for the latent heat of vaporisation between the value suggested by Masi $^{15}$ and that suggested by Lee and Kesler, ${ }^{16}$ compared with the values referred to by Anderson et al., ${ }^{7}$ in their Table $6 \cdot 2$.
A new analysis of the experimental data was performed by Guenoun et al., ${ }^{17}$ in order to recalculate the physical properties of $\mathrm{UF}_{6}$, in particular along the saturation curve, using the software presented by Le Neindre and Garrabos. ${ }^{18}$

In 2001, the French IPSN was also in the process of examining a pluri-annual plan of experimental studies on $\mathrm{UF}_{6}$ including measurement of the triple point and up to and beyond the critical point. The main stages of the plan were as follows:

(i) Obtain the phase plot by measurement of the refraction index for each phase using a technique of laser beam deflection

(ii) Measurement of the true thermal conductivities based on an observation of the differences in temperature between two heated co-axial cylinders

(iii) Determination of the adiabatic compressibility, by measuring the speed of the sound.

During 2000-2001 the IPSN and Bontemps and colleagues ${ }^{19}$ were studying the most appropriate simulant fluids. The objective was to define an experimental programme to enable the following parameters and their combinations to be tested:

(i) Rate of filling at the initial moment

(ii) Temperature of the furnace

(iii) Heating duration

(iv) Initial conditions (crust thickness and porosity). Unfortunately, the study was stopped when the new French IRSN was created.

The discussion in the present study should be considered, and it is hoped that this will result in new experimental programmes and the development of more detailed theoretical models.

In conclusion, for a $48 \mathrm{Y}$ cylinder filled to the nominal value, at the end of exposure to the regulatory $30 \mathrm{~min}$ fire test, solid, liquid and gaseous phases coexist inside the cylinder. The value of the pressure depends on the distribution of $\mathrm{UF}_{6}$ between phases. Estimation of this distribution is a complex problem that has not been adequately resolved. The TENERIFE tests were terminated before the most important portion of $\mathrm{UF}_{6}$ phase change in the cylinder could occur, by stopping the tests well before $1800 \mathrm{~s}$. 
Thus, the terms of the controversy can be expressed as follows:

a. Either the existing data and analyses related to temperatures inside the TEN4 cylinder are correct and the pressure evolution after the cessation of heating led to the conclusion that, under the conditions of the IAEA fire test, the pressure would not reach the value expected to rupture the cylinder at the end of the regulatory period of $30 \mathrm{~min}$. However, after the cessation of heating, the pressure would continue to increase for a very long time.

b. Or the existing data and analyses related to temperatures inside the TEN4 cylinder are incorrect and the oscillations of the conductivity (reported in Fig. 4), used in the simulations presented by Niel et $a l^{2,3}$ and Sert and colleagues, ${ }^{5,6}$ have a physical meaning. Then the pressure could reach the value expected to rupture the cylinder at the end of the regulatory period of $30 \mathrm{~min}$.

\section{Acknowledgements}

This work was performed while F. Werkoff was working at the IPSN. The authors would like to thank Professor M. Quintard, President of the Conseil Scientifique of the IRSN, for suggesting that this work be presented for publication.

Note from the Editor: As noted by the author in the abstract, the subject matter of the present study has been the subject of some controversy for several years. This was emphasised during the refereeing process. While the content and conclusions may not be universally accepted, it has been decided that the interests of technology and fairness would be best served by publishing the paper in its present form. The result may be to promote further discussion on all aspects of the controversy.

\section{References}

1. Atomic Energy Agency: 'Regulations for the safe transport of radioactive material', 1996 edn, Safety Standards Series No. ST-1, Atomic Energy Agency, Vienna, 1996.
2. J. C. Niel, G. Sert, B. Duret, E. Pinton, G. Berthoud, J. C. Bonnard, C. Saroul, K. Shirai and M. Wataru: 'Final report of the French/Japanese research program 'TENERIFE' about the behaviour of a UF6 cylinder in fire. Thermal results and structural resistance evaluation', Internal report DSMR/07-008, October 1997, Fontenay-aux Roses, IPSN.

3. J. C. Niel, G. Sert, B. Duret, G. Berthoud, C. Saroul, K. Shirai and M. Wataru: Proc. Comité Scientifique de l'I.P.S.N. Session of February 10, 1998, Fontenay-aux Roses, IPSN.

4. E. Pinton: 'Modelling of the behaviour of a container of uranium hexafluoride subjected to a fire', thesis, I.N.P.G., Grenoble, 12 November 1996.

5. G. Sert, P. Lelong and S. Felix: RAMTRANS, 1999, 10(4), 221230.

6. M. Livolant and G. Sert: $R G N, 1999$ (3), 5-6.

7. J. C. Anderson, C. P. Kerr and W. R. Williams: 'Correlation of the thermophysical properties of uranium hexafluoride over a wide range of temperature and pressure', ORNL/ENG/TM-51, Oak Ridge National Laboratory, Martin Marietta Energy Systems Inc, Oak Ridge, TN, August 1994.

8. J. M. Baze, S. Félix, E. Pinton and F. Werkoff: RAMTRANS, 2001, 12(1), 51-54.

9. P. Blanchard: 'Analyse du code DIBONA', Report ANCOIngéniérie A/IPSN/6559 E, June 2000, Meudon La Forêt, Anco Ingenierie.

10. F. Werkoff: 'Applicabilité du modèle DIBONA aux augmentations de pression constatées après arrêt du chauffage', Technical note IPSN/DSMR/SATE/01.852, 5 November 2001, Fontenay-aux Roses, IPSN.

11. F. Werkoff: 'Feux d'UF6, amélioration du modèle DIBONA: bilan des actions 2001 et examen de possibilités d'actions 2002', Technical note IPSN/DSMR/SATE/, December 2001, Fontenayaux Roses, IPSN

12. K. Shirai, M. Wataru and T. Saegusa: J. Nucl. Mater. Manag. (SEAS SPR), 2002, 7-13.

13. E. Pinton: 'Interprétation des résultats expérimentaux de l'essai TEN5 et comparaison avec TEN2,TEN4 et TEN6', Technical (Internal) note EURIWARE/NT/CDT/70055/0006, Montigny-LeBretonneux, France, 11 July 1997, Guyancourt, Euriware.

14. J. F. Fourmigué: 'Modélisation du comportement thermique du ciel de gaz d'un conteneur d'UF ${ }_{6}$, Technical note CEA/GRETh $n^{\circ}$ 01/799, December 2001, Grenoble, CEA.

15. J. F. Masi: J. Chem. Phys., 1949, 17(9), 755-758.

16. B. I. Lee and M. G. Kesler: AICHE J., 1975, 21(3), 510-527.

17. P. Guenoun, M. Bonetti and B. Le Neindre: 'Etude bibliographique des coordonnées du point critique de l'UF', Report CEA/ DSM/DRECAM/SPEC, 2001, Gif sur Yvette, CEA.

18. B. Le Neindre and Y. Garrabos: Fluid Phase Equilibria, 2001, 198(2), 165-183.

19. A. Bontemps, A. Maréchal and J. F. Fourmigué: 'Tenue au feu des emballages de transport d'UF6 de type 48 Y. Rapport d'avancement: étude préliminaire. Choix de fluides de simulation', Technical note CEA/GRETh $n^{\circ}$ 01/782, November 2001, Grenoble, CEA. 